\begin{abstract}
Iranica
Abstracta Iranica Revue bibliographique pour le domaine irano-aryen

Volume 37-38-39 | 2018

Comptes rendus des publications de 2014-2016
\end{abstract}

\title{
Christoph Werner. Vaqf en Iran. Aspects culturels, religieux et sociaux
}

\section{Maria Szuppe}

\section{OpenEdition}

1 Journals

\section{Édition électronique}

URL : http://journals.openedition.org/abstractairanica/46069

DOI : 10.4000/abstractairanica.46069

ISBN : 1961-960X

ISSN : 1961-960X

Éditeur :

CNRS (UMR 7528 Mondes iraniens et indiens), Éditions de l'IFRI

Référence électronique

Maria Szuppe, "Christoph Werner. Vaqf en Iran. Aspects culturels, religieux et sociaux », Abstracta Iranica [En ligne], Volume 37-38-39 | 2018, document 3, mis en ligne le 30 décembre 2018, consulté le 26 septembre 2020. URL : http://journals.openedition.org/abstractairanica/46069 ; DOI : https://doi.org/ 10.4000/abstractairanica.46069

Ce document a été généré automatiquement le 26 septembre 2020

Tous droits réservés 


\title{
Christoph Werner. Vaqf en Iran. Aspects culturels, religieux et sociaux
}

\author{
Maria Szuppe
}

\section{RÉFÉRENCE}

Christoph Werner. Vaqf en Iran. Aspects culturels, religieux et sociaux. Paris : Association pour l'Avancement des études iraniennes, 2015, 187p., 9 illustrations n\&b, bibliographie, index, résumés en anglais (p. 167-180). (Studia Iranica, Cahier 56), ISBN 978-2-910640-42-2 (Diffusion : Peeters Press)

1 L'ouvrage de Christoph Werner constitue une contribution marquante à l'histoire des fondations pieuses de mainmorte, omniprésentes dans tout le monde musulman. Dans ce volume, l'auteur analyse cette institution en Iran (vaqf; aussi mowqufāt) en adoptant une approche «longue durée » du XIV siècle à nos jours. Il propose de replacer ses recherches dans une réflexion plus large qui permet de rendre compte du caractère remarquablement pérenne et véritablement transversal de cette institution. En effet, la présence et l'influence des fondations pieuses sont ressenties dans toutes les couches sociales, toutes branches des activités économiques, toutes écoles confessionnelles de l'islam...

2 Le volume s'appuie sur une série de conférences prononcées par Ch. Werner à Paris dans le cadre des Ehsan and Latifeh Yarshater Distinguished Lectures in Iranien Studies, en 2012. Les cinq chapitres, précédés d'une introduction, reflètent les thèmes centraux des cinq conférences originales et s'intéressent aux aspects sociaux et culturels, mais aussi économiques, religieux et politiques des fondations de vaqf en Iran. Le premier chapitre soulève la question de la définition de l'institution et de son régime juridique dans le contexte iranien - où la jurisprudence chiite ne devient dominante, progressivement, qu'à partir de l'époque safavide -, ainsi que des développements de ses pratiques administratives (1. "L'institution du vaqf en Iran», p. 35-68). Le chapitre suivant s'intéresse au rôle qu'ont joué les fondations pieuses, à la fin de l'époque médiévale et 
au début de l'époque moderne, dans le processus de la formation et de la consolidation des communautés et lignées soufies, puis dans l'affermissement du pouvoir politique (2. «Mouvements mystiques et fondations pieuses: les Kujuji et les Safavides au $14^{\mathrm{e}}$ siècle ", p. 69-92). Les deux chapitres suivants sont consacrés à l'analyse des aspects matériels, mais aussi des pratiques diplomatiques et des manifestations d'émancipation politique des fondations majeures vis-à-vis de l'État, à l'époque moderne (3. «Ville de lumière : Machhad et ses fondations d'illumination », p. 93-113; 4. «Robes d'honneur conférées par l'Imam Reżā », p. 115-134). Enfin, le dernier chapitre étudie les voies par lesquelles le vaqf a réussi à concilier des idéologies modernes, notamment nationalistes mais aussi modernisatrices, avec les stipulations légales islamiques tout en maintenant les objectifs religieux (charité) et économiques (immobilisation des biens hors du marché achat-vente normal) de l'institution au cours du XXe siècle (5. «Mécénat, instruction publique et le vaqf à l'époque pahlavi », p. 135-166).

L'auteur exploite une riche documentation primaire, publique et privée, notamment les actes de constitution en bien de mainmorte (vaqfnāma), les recueils de documents et archives de gestion des fondations pieuses (notamment de l'Astān-e Qods à Mashhad), mais aussi d'autres sources d'histoire sociale et politique telles que les chroniques ou hagiographies. Par ailleurs, il faut souligner que le travail d'édition et la présentation $\mathrm{du}$ texte sont très soignés, et les coquilles restent rares.

\section{AUTEURS}

\section{MARIA SZUPPE}

CNRS, Mondes iranien et indien, Paris 